\title{
Possible Control of Potato Common Scab with Indigenous Nonpathogenic Species of Streptomyces in Egypt
}

\section{Abd El-Hafez, O.A. and Abd El-Rahman, A.F.}

Bacterial Dis. Res. Dept., Plant Pathology Research Institute, Agricultural Research Center, Giza, Egypt.

The potato common scab disease became a major threat for potato 1 raised in light soil(s) in Egypt. In the present work, eight out of twenty-five isolates of Streptomyces recovered from four locations and rhizosphere soil of three different crops showed antagonistic potential against Streptomyces scabies. The partial 16S rRNA gene sequences of five of these eight isolates showed 99.13 to $99.67 \%$ similarity with Streptomyces rochei strain NRRL B-1559.The other three isolates showed 99.73, 99.60, and100 \% similarity with Streptomyces geysiriensis strain NRRL_B-12102, Streptomyces tunisiensis strain CN-207, and Streptomyces djakartensis strain NBRC 15409 , respectively. The partial $16 \mathrm{~S}$ rRNA gene sequences of the eight antagonistic isolates have been deposited in the GenBank of the National Center for Biotechnology Information (NCBI) under the accession numbers MT878417, MT878546, MT878545, MT878152, MT878547, MT878450, MT878478, and MT878497. The inhibition zones of the growth of Streptomyces scabies by the eight selected antagonistic isolates of Streptomyces were variably from 32.7 to 66.7 mm. Application of Streptomyces geysiriensis 7AS_GP8, Streptomyces tunisiensis 8AS_BNM2, Streptomyces djakartensis 4AS_MO2, and Streptomyces rochei 5AS_MO3 in pots experiment significantly decreased scab index from $68.6 \%$ in control treatment to 39.1, 47.7, 25.3, and 31.7\%, respectively. Streptomyces djakartensis 4AS_MO2 gave the pronounced decrease $(63.1 \%)$ in disease followed by Streptomyces rochei 5AS_MO3 (53.8 \%), Streptomyces geysiriensis 7AS_GP8 (42.9 \%), and Streptomyces tunisiensis 8AS_BNM2 (30.4\%), respectively. Streptomyces djakartensis 4AS_MO2 and Streptomyces rochei 5AS_MO3 provided promising results as potential biocontrol agents against Streptomyces scabies. Further field studies may be advised.

Keywords: Potato, Streptomyces scabies, Biological control, Streptomyces geysiriensis, Streptomyces tunisiensis, Streptomyces djakartensis, Streptomyces rochei.

Streptomyces is a genus embracing (over 500 species) gram-positive microorganisms affiliated to the order Actinomycetales and the family Streptomycetaceae. Streptomyces are filamentous organisms and have the potential to produce bioactive secondary metabolites, especially antibiotics. The productions 
of the bioactive secondary metabolites are important for Streptomyces in order to compete with other microorganisms even within the same genus (Procopio et al. 2012). Streptomyces spp. are viewed as free-living soil bacteria, and some species symbiosis with animals, plants, insects, and fungi and some strains live in marine soil. A few species of Streptomyces are plant pathogens, and the most economically important disease caused by Streptomyces species is the potato scab. Symptoms of potato scab are lesions (raised, pitted, or superficial) formed on the surface of tubers (Zhang and Loria, 2017).

Potato (Solanum tuberosum L.) is the most important food crop after cereals. Total world potato production is estimated at approximately four hundred million tons in 2017, of which about four and a half million tons were contributed by Egypt. Egypt ranks among the world's top potato exporters. Some diseases causing blemishes on the surface of the tubers reducing marketing ability (Arora and Khurama, 2004 and FAOSTAT, 2018). Many species of the genus Streptomyces as S. scabies, $S$. turgidiscabies, $S$. acidiscabies, $S$. ipomoeae (the causal agent of soft rot disease in sweet potatoes), S. europaeiscabiei, S. stelliscabiei, S. luridiscabiei, S. puniciscabiei, S. niveiscabiei, S. reticuliscabiei, and $S$. caviscabies cause scab or scab-like disease (s). The oldest and the most studied species of Streptomyces known to cause scab is Streptomyces scabies (Zhang and Loria, 2017). The Common scab of potatoes was placed among the most five serious diseases of potatoes (SagovaMareckova et al., 2015). This disease occurs worldwide and affects the quality of tubers due to lesions that are formed on the tuber surface. The potato scab disease has become a major problem for potato growers in Egypt, especially in the last few years (El-Sheikh et al., 2012 and Abd El-Rahman et al. 2018). El-Sheikh, 2010 found that the incidence and severity of common scab were ranged from 22.5 to 60.0 $\%$ and 11.4 to $25.8 \%$, respectively in three surveyed governorates El-Behera, ElSharkia and El-Ismailia.

Control strategies of potato common scab are challenging due to limited understanding of the genetic diversity of $S$. scabies and genetic differences in various potato cultivars. Traditional control methods such as lowering soil $\mathrm{pH}$, increasing irrigation intensity, and cultural practices such as crop rotation as well as chemical control methods are not usually effective. Several studies have used biocontrol agents such as Pseudomonas spp., Bacillus spp., and nonpathogenic Streptomyces spp. to control potato common scab. (Lin et al., 2018). Some nonpathogenic Streptomyces spp. were used to control pathogenic Streptomyces strains that cause potato common scab (Hiltunen et al., 2009 and Wanner et al., 2014).

The objective of this work was isolation and identification of nonpathogenic Streptomyces spp. from the rhizosphere of different crops at different locations in Egypt. Screening the antimicrobial activity of the nonpathogenic Streptomyces spp.

Egypt. J. Phytopathol., Vol. 47, No. 1 (2019) 
against Streptomyces scabies. Studying the biocontrol potential of nonpathogenic Streptomyces spp. on common scab severity.

\section{Materials and Methods}

Source of the pathogenic isolate of Streptomyces scabies:

The pathogenic isolate of Streptomyces scabies (T-47) was previously isolated from naturally infected potato tubers and identified by Mahdy et al. (2014). The pathogenicity test was re-performed on radish seedlings and leaf-bud cutting method (Lorang et al., 1995) to check virulence.

Isolation of nonpathogenic isolates of Streptomyces:

Nonpathogenic isolates of Streptomyces were isolated from the rhizosphere of different crops at different locations in Egypt using the serial dilution technique (Arifuzzaman et al. 2010 Rahman et al. 2011 and Janaki et al. 2014). The rootsadhering soil was collected and air-dried under room temperature for one week. One $\mathrm{g}$ soil in $10 \mathrm{ml}$ of sterilized distilled water was heated in a water bath at $50^{\circ} \mathrm{C}$ for 10 min and serially diluted up to $10^{-6}$ in sterile distilled water. A $100 \mu \mathrm{l}$ of soil dilution was plated out on starch casein agar (SCA) medium (starch $10 \mathrm{~g}, \mathrm{KNO}_{3} 2 \mathrm{~g}$, casein $0.3 \mathrm{~g}, \mathrm{~K}_{2} \mathrm{HPO}_{4} 2 \mathrm{~g}, \mathrm{MgSO}_{4} .7 \mathrm{H}_{2} \mathrm{O} 0.05 \mathrm{~g}, \mathrm{NaCl} 2 \mathrm{~g}, \mathrm{CaCO}_{3} 0.02 \mathrm{~g}, \mathrm{FeSO}_{4} \cdot 7 \mathrm{H}_{2} \mathrm{O} 0.01$ $\mathrm{g}$, agar $20 \mathrm{~g}$, distilled water $1000 \mathrm{ml}$ and $\mathrm{pH}$ 7.2) supplemented with cycloheximide $(100 \mu \mathrm{g} / \mathrm{ml})$ and incubated at $28^{\circ} \mathrm{C}$. The medium was checked for the growth of typical Streptomyces colonies up to 14 days. Single colonies of Streptomyces were transferred to Petri dishes of glucose-yeast extract malt (GYM) agar medium (glucose $4 \mathrm{~g}$, yeast extract $4 \mathrm{~g}$, malt extract $10 \mathrm{~g}$, agar $20 \mathrm{~g}$, distilled water $1000 \mathrm{ml}$ and $\mathrm{pH}$ 7.2) and incubated at $28^{\circ} \mathrm{C}$ for 7 days. Subsequent transfer to fresh GYM agar medium was done using the streak-plate technique to obtain pure cultures.

Screening of antimicrobial activity of Streptomyces isolates:

Preliminary screening for antimicrobial activity of the Streptomyces isolates was carried out on the GYM agar medium. Isolates were grown separately in the GYM agar medium at $28^{\circ} \mathrm{C}$ for 7 days. Five milliliters suspension $\left(10^{8} \mathrm{CFU} / \mathrm{ml}\right)$ of Streptomyces scabies were used as inoculum for a flask containing $250 \mathrm{ml}$ of melted GYM agar medium. Twenty milliliters of GYM were poured into each Petri dish. A loopful of growth of tested Streptomyces isolate was spot inoculated at the center of Petri dish containing GYM agar previously inoculated with Streptomyces scabies. The Petri dishes were incubated at $28^{\circ} \mathrm{C}$ for 3 days. The inhibition zone around the growth of the tested Streptomyces isolate was recorded as a positive (+) reaction (Abd El-Rahman and Shaheen 2016).

Identification of the Streptomyces isolates using $16 S$ rRNA analysis:

Eight selected Streptomyces isolates were sent to Sigma Scientific Services Co., Giza, Egypt for 16S rRNA analysis as follows: 


\section{DNA extraction}

DNA of each Streptomyces isolate was extracted using Quick-DNATM Miniprep Plus Kit (Zymo Research Corporation, USA) according to the manufacturer's protocol. Water $(95 \mu \mathrm{l})$, solid tissue buffer (blue, $95 \mu \mathrm{l})$ and proteinase $\mathrm{K}(10 \mu \mathrm{l})$ were added to $200 \mu \mathrm{l}$ liquid media containing Streptomyces isolate in a microcentrifuge tube. Then the contents of the tube were mixed thoroughly and incubated at $55^{\circ} \mathrm{C}$ for 2 hours. Then the contents of the tube were mixed thoroughly again and centrifuged at $12000 \mathrm{xg}$ for 1 minute. The aqueous supernatant $(300 \mu \mathrm{l})$ was transferred to a clean tube and $600 \mu \mathrm{l}$ genomic binding buffer was added. Then the contents of the tube were mixed thoroughly, transferred to a Zymo-Spin ${ }^{\mathrm{TM}}$ IICXL Column in a collection tube and centrifuged at $(\geq 12000 \mathrm{xg}$ ) for 1 minute (Lee et al., 2003). The collection tube was discarded, with the flowing through it. DNA PreWash Buffer $(400 \mu \mathrm{l})$ was added to the column in a new collection tube, and centrifuged at $(12000 \mathrm{xg})$ for 1 minute. The collection tube was emptied, g-DNA Wash Buffer $700 \mu \mathrm{l}$ was added and centrifuged at $(12000 \mathrm{xg})$ for 1 minute. The collection tube was emptied, g-DNA Wash Buffer $(200 \mu \mathrm{l})$ was added, centrifuged at $(12000 \mathrm{xg})$ for 1 minute, the collection tube was discarded, with the flowing through it. The spin column was transferred to a clean microcentrifuge tube, elution buffer $(30 \mu \mathrm{l})$ was added, incubated for 5 minutes at room temperature, and then centrifuged at $(12.000 \mathrm{xg})$ for 1 minute to elute the DNA (Lee et al., 2003).

\section{PCR amplification}

Amplification of the $16 \mathrm{~S}$ rRNA gene was carried out using a Thermo Scientific $^{\mathrm{TM}}$ Arktik $^{\mathrm{TM}}$ Thermal Cycler (Thermo Fisher Scientific Oy, Finland) with a $50 \mu \mathrm{l}$ reaction mixture containing $25 \mu \mathrm{l}$ My Taq Red Mix, $8 \mu \mathrm{L}$ DNA template, 15 $\mu \mathrm{l}$ nuclease free water, $1 \mu \mathrm{l}(20 \mathrm{Pico}$ mol) forward primer F1 (5'AGAGTTTGATCITGGCTCAG-3'; $\mathrm{I}=$ inosine) and $1 \mu \mathrm{l}$ (20 Pico mol) reverse primer R5 (5'-ACGGITACCTTGTTACGACTT-3') (Cook and Meyers, 2003). The PCR program was set as follows: an initial denaturation step at $94{ }^{\circ} \mathrm{C}$ for $6 \mathrm{~min} ; 35$ cycles at $94{ }^{\circ} \mathrm{C}$ for $45 \mathrm{~s}, 56{ }^{\circ} \mathrm{C}$ for $45 \mathrm{~s}, 72^{\circ} \mathrm{C}$ for $1 \mathrm{~min}$, followed by a final extension at $72^{\circ} \mathrm{C}$ for $5 \mathrm{~min}$.

\section{DNA purification and Sequencing}

PCR products were purified using the DNA Clean \& Concentrator-5 Kit procedure (Zymo Research Corporation, USA) according to the manufacturer's instructions. DNA was sequenced using ABI 3730xl DNA Sequencer (Applied Biosystems, Foster City, CA, USA) in GATC Company, Germany.

\section{BLAST search and GenBank (NCBI) accession numbers:}

The partial 16S rRNA gene sequences of the eight selected antagonistic isolates of Streptomyces were compared with the sequences in the GenBank of the National Center for Biotechnology Information (NCBI) by BLAST program (https://blast.ncbi.nlm.nih.gov/Blast.cgi) using the database of 16S ribosomal RNA sequences (Bacteria and Archaea) using Megablast (Optimize for highly similar 
sequences) for alignments. DECIPHER version 2.17.1 was employed for chimeras check (Wright et al., 2012). The partial 16S rRNA gene sequences of the eight tested antagonistic isolates of Streptomyces were submitted to GenBank of the NCBI to receive the accession numbers.

The multiple alignment and preparing phylogenetic trees:

Multiple alignment and phylogenetic reconstructions were performed by the Multiple Clustal Alignment software from ClustalW (https://www.genome.jp/toolsbin/clustalw) using the function "build" of The Environment for Tree Exploration ETE3 v3.1.1 (Huerta-Cepas et al., 2016) as implemented on the Genome Net (https://www.genome.jp/tools/ete/). ML (Maximum likelihood) tree of the selected isolates of Streptomyces were inferred using Randomized Axelerated Maximum Likelihood RAxML v8.1.20 ran with model GTRGAMMA and default parameters (Stamatakis, 2014). Branch supports were computed out of 100 bootstrapped trees. ML (Maximum likelihood) tree of the selected isolates of Streptomyces and the closely related reference strains in GenBank of the NCBI was inferred using PhyML v20160115 ran with model and parameters: --alpha e -o tlr -nclasses 4 --bootstrap 100 --pinv e -f m (Guindon et al., 2010). Branch supports are computed out of 100 bootstrapped trees.

Measurement of the inhibition ability of Streptomyces isolates on the growth of Streptomyces scabies:

The same previous method used in the screening of antimicrobial activity of Streptomyces isolates was used to measure the inhibition ability of selected Streptomyces isolates on the growth of Streptomyces scabies in vitro. A loopful of growth of tested Streptomyces isolate was spot inoculated at the center of Petri dish containing GYM agar previously inoculated with Streptomyces scabies. The experiment was performed in three replicates. The Petri dishes were incubated at $28^{\circ} \mathrm{C}$ for 3 days. The inhibition zone around the growth of tested Streptomyces isolate was recorded in millimeters $(\mathrm{mm})$.

Pots experiment:

Disease-free potato seed tubers (cv. Spunta) were obtained from potato brown rot project (PBRP), ARC, Egypt. The seed tubers were planted in Pots $(20 \mathrm{~cm}$ in diam.) filled with infested soil mixture (sand: clay: compost at 2: 1: 1 ratio $\mathrm{v} / \mathrm{v} / \mathrm{v}$ ) with Streptomyces scabies. The latter inoculum was prepared by inoculating $50 \mathrm{ml}$ of GYM broth in a flask $(250 \mathrm{ml})$ with $1 \mathrm{ml}$ water suspension $\left(10^{6} \mathrm{CFU} / \mathrm{ml}\right)$ of Streptomyces scabies spores harvested from a 3-week old GYM agar plate. The flask was shake incubated for 5 days at $28^{\circ} \mathrm{C}$. Cells were pelleted by centrifugation at $9000 \mathrm{xg}$ and resuspended in $150 \mathrm{ml}$ sterile distilled water. Five milliliters of this resuspended cells and $50 \mathrm{ml}$ of sterile solution (sucrose $40 \mathrm{~g}$, asparagine $2.4 \mathrm{~g}$, K2HPO4 $1.2 \mathrm{~g}$, yeast extract $20 \mathrm{~g}$ in $1000 \mathrm{ml}$ of sterile distilled water) were added to a bag containing $300 \mathrm{~cm}^{3}$ of sterile vermiculite. Infested vermiculite bags were incubated for 14 days at $28^{\circ} \mathrm{C}$, with regular shaking every other day during 
incubation. After 14 days of incubation, the vermiculite bags were checked using the serial dilution technique to ensure even distribution of Streptomyces and to estimate inoculum density. Vermiculite inoculum containing $10^{10} \mathrm{CFU} / \mathrm{g}$ of Streptomyces scabies was added to the soil mixture (Vermiculite inoculum : soil mixture : at $1: 9$ ratio v/v) and mixed thoroughly (Wanner, 2007). Antagonistic isolates were propagated separately in GYM broth by shaking for 5 days at $28^{\circ} \mathrm{C}$. Cells were pelleted by centrifuged at $9000 \mathrm{xg}$ and were resuspended in sterile distilled water to adjust the inoculum $\left(10^{6} \mathrm{CFU} / \mathrm{ml}\right)$ concentration (Sarwar et al., 2019). The pots were drenched with $100 \mathrm{ml} /$ pot of antagonistic isolate suspension, with 5 replicates (3 pots each) after planting potato tubers. Control plants (without antagonistic applications) were considered in the experiment. Plants kept without Streptomyces scabies and antagonistic isolates were used as a negative control treatment .

Potato tubers were harvested after 100 days of seeding. The scab index was determined and the percent of disease decrease was estimated as described by Abd El-Rahman et al. (2018).

Where:

$$
\text { Scab index } \%=(0 \mathrm{~A}+1 \mathrm{~B}+2 \mathrm{C}+3 \mathrm{D}+4 \mathrm{E} / 4 \mathrm{~T}) \times 100
$$

$0=$ no scab; $1=$ trace- $10 \%$ tuber surface is scabbed; $2=11-25 \%$ tuber surface is scabbed; $3=26-50 \%$ tuber surface is scabbed; $4=$ more than $50 \%$ tuber surface is scabbed; A, B, C, D, and E are the number of tubers in grades $0,1,2,3$ and 4 respectively; $\mathrm{T}=$ is the total number of tubers.

Disease decrease $\%=[($ scab index in control-scab index in treatment $) /$ scab index in control) X 100.

Statistical analysis:

Completely randomized design was used in all experiments. The collected data were subjected to one-way analysis of variance (ANOVA) as illustrated by Snedecor and Cochran (1989). LSD values were used to compare the means at probability (P) value of $\leq 0.05$.For performing the mentioned statistical analysis, SPSS version 13.0 (SPSS Inc. Chicago, IL, USA) statistical packages were used.

\section{Results}

Source and antimicrobial activity of the Streptomyces isolates:

Twenty-five isolates of Streptomyces, recovered from four different locations (Manshet Radwan, El Nubaria, Al-Wasta, and Mallawi) and rhizosphere soil of three different crops (Potato, maize, and onion) in Egypt, were tested for their ability to inhibit the growth of Streptomyces scabies in vitro. Eight isolates (GP8, BP1, BP6, BNM2, MO1, MO2, MO3, and MO4) out of the twenty-five showed potential to inhibit the growth of Streptomyces scabies. Three out of the eight isolates were isolated from the rhizosphere of potato plants, one (GP8) from Giza governorate (Manshet Radwan) and two (BP1, BP6) from Beheira governorate (El Nubaria).The other five isolates were selected, one (BNM2) from the rhizosphere of maize plants from Beni Suef governorate (Al-Wasta), and the other four (MO1, MO2, MO3, and 
MO4) from the rhizosphere of onion plants from Minya governorate (Mallawi) (Table 1).

16S rRNA analysis and GenBank (NCBI) accession numbers:

The partial 16S rRNA gene sequences of the eight selected antagonistic solates of Streptomyces recovered from the rhizosphere of potato, maize, and onion from four governorates in Egypt compared to the sequences in the NCBI database are shown in (Table 2).The sequence of GP8 showed $99.73 \%$ similarity with Streptomyces geysiriensis strain NRRL_B-12102. While the sequences of BP1, BP6, MO1, MO3, and MO4 showed 99.67, 99.67, 99.67, 99.67, and 99.13\% similarity with Streptomyces rochei strain NRRL B-1559, respectively. The sequence of BNM2 showed $99.60 \%$ similarity with Streptomyces tunisiensis strain CN-207. Also, the sequence of MO2 showed $100 \%$ similarity with Streptomyces djakartensis strain NBRC 15409.

Table (1): Source of Streptomyces isolates and their antibacterial potential against Streptomyces scabies

\begin{tabular}{|c|c|c|c|c|}
\hline $\begin{array}{l}\text { Isolate } \\
\text { code }\end{array}$ & Location & Governorate & $\begin{array}{c}\text { plant } \\
\text { rhizosphere }\end{array}$ & $\begin{array}{c}\text { Antibacterial ability against } \\
\text { Streptomyces scabies* }\end{array}$ \\
\hline GP1 & Manshet Radwan & Giza & Potato & - \\
\hline GP2 & Manshet Radwan & Giza & Potato & - \\
\hline GP3 & Manshet Radwan & Giza & Potato & - \\
\hline GP4 & Manshet Radwan & Giza & Potato & - \\
\hline GP5 & Manshet Radwan & Giza & Potato & - \\
\hline GP6 & Manshet Radwan & Giza & Potato & - \\
\hline GP7 & Manshet Radwan & Giza & Potato & - \\
\hline GP8 & Manshet Radwan & Giza & Potato & + \\
\hline BP1 & El Nubaria & Beheira & Potato & + \\
\hline $\mathrm{BP} 2$ & El Nubaria & Beheira & Potato & - \\
\hline BP3 & El Nubaria & Beheira & Potato & - \\
\hline BP4 & El Nubaria & Beheira & Potato & - \\
\hline BP5 & El Nubaria & Beheira & Potato & - \\
\hline BP6 & El Nubaria & Beheira & Potato & + \\
\hline BP7 & El Nubaria & Beheira & Potato & - \\
\hline BNM1 & Al-Wasta & Beni Suef & Maize & - \\
\hline BNM2 & Al-Wasta & Beni Suef & Maize & + \\
\hline BNM3 & Al-Wasta & Beni Suef & Maize & - \\
\hline BNM4 & Al-Wasta & Beni Suef & Maize & - \\
\hline MO1 & Mallawi & Minya & Onion & + \\
\hline MO2 & Mallawi & Minya & Onion & + \\
\hline MO3 & Mallawi & Minya & Onion & + \\
\hline $\mathrm{MO} 4$ & Mallawi & Minya & Onion & + \\
\hline MO5 & Mallawi & Minya & Onion & - \\
\hline MO6 & Mallawi & Minya & Onion & - \\
\hline
\end{tabular}

*Negative reaction $(-)$, Positive reaction $(+)$. 
Table (2): Comparison of partial 16S rRNA gene sequences of the eight selected antagonistic isolates of Streptomyces recovered from four locations and rhizosphere soil of three different crops in Egypt with the sequences in GenBank (NCBI)

\begin{tabular}{|c|c|c|}
\hline Isolate code & Identification by 16S rRNA sequence analysis & $\begin{array}{c}\text { Similarity } \\
(\%)\end{array}$ \\
\hline GP8 & Streptomyces geysiriensis strain NRRL_B-12102 & $99.73 \%$ \\
\hline BP1 & Streptomyces rochei strain NRRL B-1559 & $99.67 \%$ \\
\hline BP6 & Streptomyces rochei strain NRRL B-1559 & $99.67 \%$ \\
\hline BNM2 & Streptomyces tunisiensis strain CN-207 & $99.60 \%$ \\
\hline MO1 & Streptomyces rochei strain NRRL B-1559 & $99.67 \%$ \\
\hline MO2 & Streptomyces djakartensis strain NBRC 15409 & $100 \%$ \\
\hline MO3 & Streptomyces rochei strain NRRL B-1559 & $99.67 \%$ \\
\hline MO4 & Streptomyces rochei strain NRRL B-1559 & $99.13 \%$ \\
\hline
\end{tabular}

The partial 16S rRNA gene sequences of the eight selected antagonistic isolates of Streptomyces GP8, BP1, BP6, BNM2, MO1, MO2, MO3, and MO4 have been deposited in GenBank (NCBI) under the accession numbers MT878417, MT878546, MT878545, MT878152, MT878547, MT878450, MT878478, and MT878497, respectively (Table 3).

Table (3): Accession numbers to the GenBank (NCBI) for the eight selected antagonistic isolates of Streptomyces

\begin{tabular}{|c|c|c|}
\hline code & Isolate & $\begin{array}{c}\text { Accession } \\
\text { number }\end{array}$ \\
\hline GP8 & Streptomyces geysiriensis 7AS_GP8 & MT878417 \\
\hline BP1 & Streptomyces rochei $2 \mathrm{AS}$ BP1 & MT878546 \\
\hline BP6 & Streptomyces rochei 1 AS_BP6 & MT878545 \\
\hline BNM2 & Streptomyces tunisiensis 8AS_BNM2 & MT878152 \\
\hline MO1 & Streptomyces rochei 3AS_MO1 & MT878547 \\
\hline MO2 & Streptomyces djakartensis 4AS_MO2 & MT878450 \\
\hline MO3 & Streptomyces rochei 5AS_MO3 & MT878478 \\
\hline MO4 & Streptomyces rochei 6AS_MO4 & MT878497 \\
\hline
\end{tabular}

Multiple alignment and Phylogenetic analysis:

The alignment scores between eight selected antagonistic isolates of Streptomyces are shown in (Table 4). The alignments scores between Streptomyces geysiriensis 7AS_GP8 and the five isolates of Streptomyces rochei i.e., 2AS_BP1, 1AS_BP6, 3AS_MO1, 5AS_MO3, and 6AS_MO4 were ranged from 98 to 99. The alignments scores between Streptomyces geysiriensis 7AS_GP8 and the two isolates Streptomyces tunisiensis 8AS_BNM2 and Streptomyces djakartensis 4AS_MO2 were 93 and 36, respectively. While the alignments scores between the five isolates Egypt. J. Phytopathol., Vol. 47, No. 1 (2019) 
of Streptomyces rochei, 2AS_BP1, 1AS_BP6, 3AS_MO1, 5AS_MO3, and 6AS_MO4 were 99. The alignments scores between the five previous isolates and the two isolates Streptomyces tunisiensis 8AS_BNM2 and Streptomyces djakartensis 4AS_MO2 ranged from 96 to 97 and 53 to 54, respectively. Also, the alignments score between Streptomyces tunisiensis 8AS_BNM2 and Streptomyces djakartensis 4AS_MO2 was 42.

Phylogenetic analysis of the sequence data of the eight selected antagonistic isolates of Streptomyces revealed that all isolates were located in two distinct clusters (Fig. 1). Cluster 1 consisted of Streptomyces djakartensis 4AS_MO2. Whereas Cluster 2 comprised the isolates of Streptomyces rochei (3AS_MO1, 1AS_BP6, 5AS_MO3, 2AS_BP1, and 6AS_MO4), Streptomyces tunisiensis 8AS_BNM2, and Streptomyces geysiriensis 7AS_GP8. Streptomyces tunisiensis 8AS_BNM2 and Streptomyces geysiriensis 7AS_GP8 formed a separate cluster within the main Cluster 2.

The phylogenetic analysis of the sequences data of the eight selected antagonistic isolates of Streptomyces and the closely related reference strains in GenBank of the NCBI revealed that all eight isolates and their closely related reference strains were located in two distinct clusters (Fig. 2). Cluster 1 consisted of the isolate Streptomyces tunisiensis 8AS_BNM2 and the closely related reference strain Streptomyces tunisiensis CN-207. Whereas Cluster 2 comprised the isolates Streptomyces djakartensis 4AS_MO2, Streptomyces geysiriensis 7AS_GP8, and the isolates of Streptomyces rochei (3AS_MO1, 1AS_BP6, 5AS_MO3, 6AS_MO4, and 2AS_BP1) as well the closely related reference strains, Streptomyces djakartensis NBRC 15409, Streptomyces geysiriensis NRRL_B-12102, and Streptomyces rochei NRRL B-1559. Streptomyces djakartensis 4AS_MO2 and Streptomyces djakartensis NBRC 15409 formed a separate cluster within the main Cluster 2.

Table (4): The alignment score in between the eight selected antagonistic isolates of Streptomyces

\begin{tabular}{|c|c|c|c|c|c|c|c|c|}
\hline Sequence & $\begin{array}{c}\text { 6AS } \\
\text { MO4 } \\
* *\end{array}$ & $\begin{array}{c}\mathrm{AS} \\
\mathrm{MO} 3 \\
* *\end{array}$ & $\begin{array}{l}4 \mathrm{AS}_{-} \\
\mathrm{MO} 2 \\
* * * *\end{array}$ & $\begin{array}{c}3 \mathrm{AS}_{-} \\
\mathrm{MO} 1 \\
* *\end{array}$ & $\begin{array}{c}8 \mathrm{AS}_{-} \\
\mathrm{BNM} 2 \\
* * *\end{array}$ & $\begin{array}{c}1 \mathrm{AS} \\
\mathrm{BP} 6 \\
* *\end{array}$ & $\begin{array}{c}2 \mathrm{AS} \\
\mathrm{BP} 1 \\
* *\end{array}$ & $\begin{array}{c}\text { 7AS } \\
\text { GP8 } \\
*\end{array}$ \\
\hline 7AS_GP8* & 98 & 99 & 36 & 99 & 93 & 99 & 99 & 100 \\
\hline 2AS_BP1 $* *$ & 99 & 99 & 54 & 99 & 97 & 99 & 100 & - \\
\hline 1AS_BP6 $* *$ & 99 & 99 & 54 & 99 & 97 & 100 & - & - \\
\hline 8AS_BNM2 $* * *$ & 96 & 97 & 42 & 97 & 100 & - & - & - \\
\hline 3AS_MO1 $* *$ & 99 & 99 & 54 & 100 & - & - & - & - \\
\hline 4AS_MO2 **** & 53 & 54 & 100 & - & - & - & - & - \\
\hline 5AS_MO3 $* *$ & 99 & 100 & - & - & - & - & - & - \\
\hline 6AS_MO4 ** & 100 & - & - & - & - & - & - & - \\
\hline \multicolumn{3}{|c|}{$\begin{array}{l}* \text { Streptomyces geysiriensis } \\
* * * \text { Streptomyces tunisiensis }\end{array}$} & \multicolumn{5}{|c|}{$\begin{array}{c}* * \text { Streptomyces rochei } \\
* * * * \text { Streptomyces djakartensis }\end{array}$} & \\
\hline
\end{tabular}

Egypt. J. Phytopathol., Vol. 47, No. 1 (2019) 


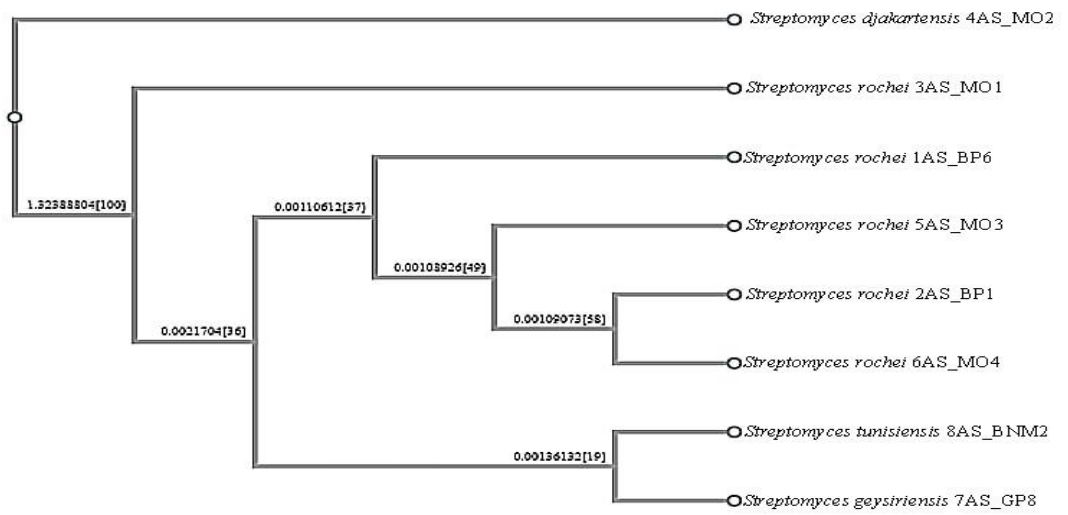

Fig. (1): Maximum likelihood phylogenetic tree based on 16S rRNA multiple sequence alignment of the eight selected antagonistic isolates of Streptomyces

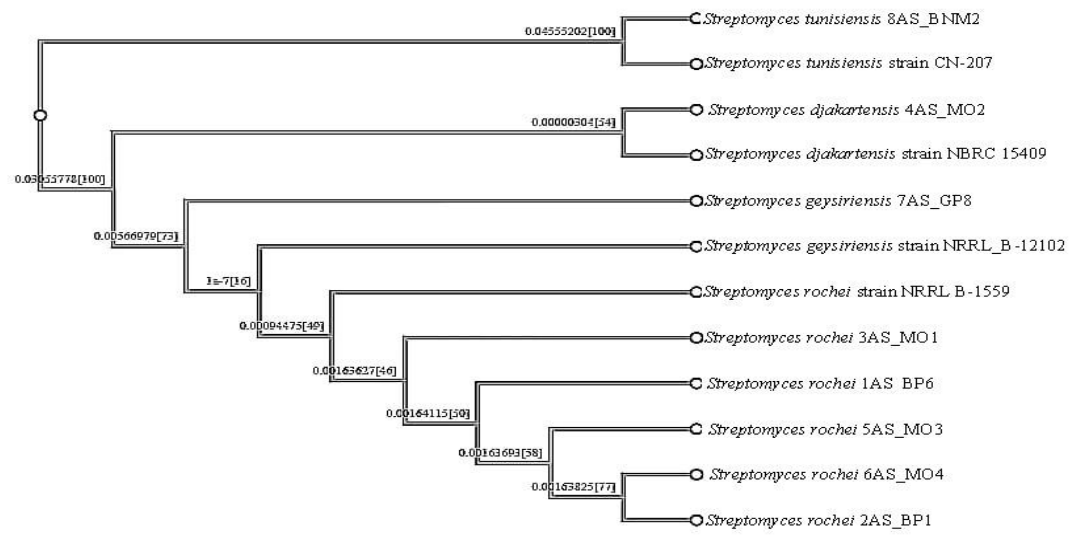

Fig. (2): Maximum likelihood phylogenetic tree based on 16S rRNA multiple sequence alignment of the eight selected antagonistic isolates of Streptomyces and the closely related reference strains in the GenBank of the NCBI

Inhibition potential of Streptomyces isolates for growth of Streptomyces scabies:

The results in Table (5) showed that the eight selected nonpathogenic isolates of Streptomyces can inhibit the growth of Streptomyces scabies on GYM agar medium with different inhibition zone diameters. The diameters of inhibition zones ranged from 32.7 to $66.7 \mathrm{~mm}$. The maximum inhibition zone diameter $(66.7 \mathrm{~mm})$ was

Egypt. J. Phytopathol., Vol. 47, No. 1 (2019) 
recorded by the Streptomyces djakartensis 4AS_MO2. The Streptomyces rochei isolates recorded inhibition zones diameter ranged from 54.3 to $63.3 \mathrm{~mm}$. The Streptomyces geysiriensis 7AS_GP8 recorded an inhibition zone diameter of 51.0 $\mathrm{mm}$. The minimum inhibition zone diameter $(32.7 \mathrm{~mm})$ was recorded by the Streptomyces tunisiensis 8AS_BNM2 (Fig. 3).

Table (5): Antagonism of eight isolates of Streptomyces to the growth of Streptomyces scabies in vitro

\begin{tabular}{|l|c|}
\hline \multicolumn{1}{|c|}{ Isolate } & $\begin{array}{c}\text { Inhibition zone } \\
(\mathrm{mm})\end{array}$ \\
\hline Streptomyces geysiriensis 7AS_GP8 & 51.0 \\
\hline Streptomyces rochei 2AS_BP1 & 54.3 \\
\hline Streptomyces rochei 1AS_BP6 & 54.3 \\
\hline Streptomyces tunisiensis 8AS_BNM2 & 32.7 \\
\hline Streptomyces rochei 3AS_MO1 & 57.7 \\
\hline Streptomyces djakartensis 4AS_MO2 & 66.7 \\
\hline Streptomyces rochei 5AS_MO3 & 63.3 \\
\hline Streptomyces rochei 6AS_MO4 & 62.0 \\
\hline L.S.D. 0.05 & 4.70 \\
\hline
\end{tabular}
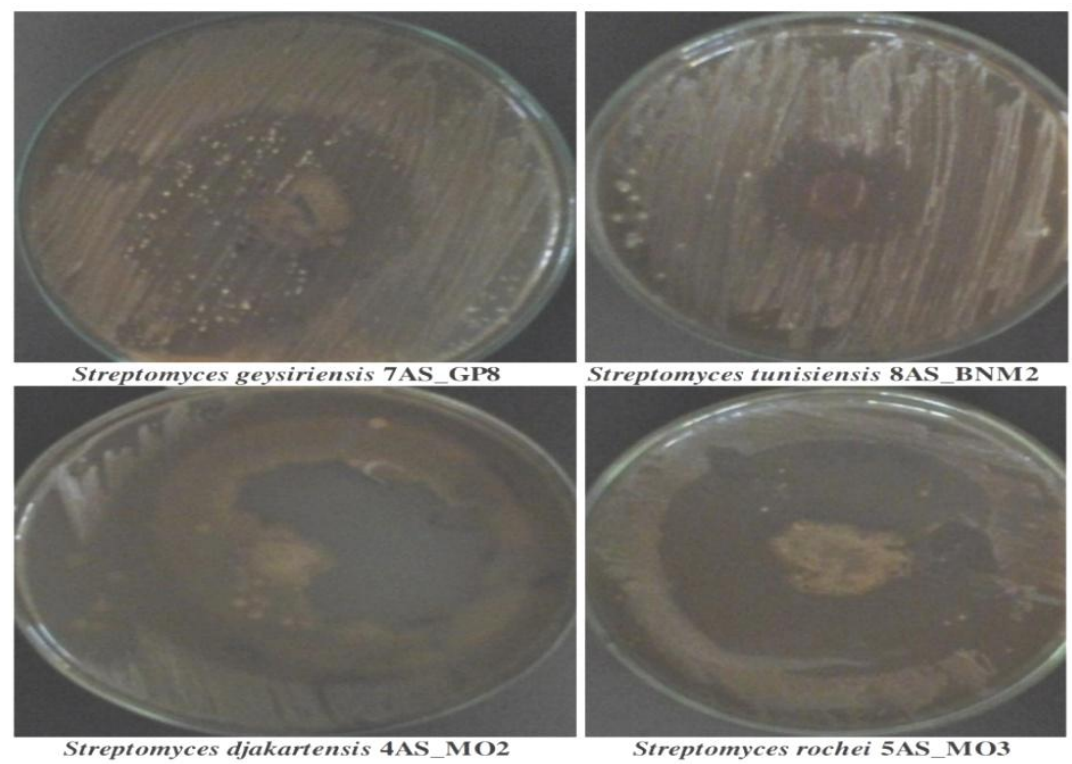

Fig. (3): Inhibition of Streptomyces scabies by isolates of non-pathogenic species of Streptomyces on GYM agar medium 
Influence of different isolates of non-pathogenic species of Streptomyces on common scab severity:

Application of Streptomyces geysiriensis 7AS_GP8, Streptomyces tunisiensis 8AS_BNM2, Streptomyces djakartensis 4AS_MO2, and Streptomyces rochei 5AS_MO3 in pots significantly decreased scab index from $68.6 \%$ in control treatment to $39.1,47.7,25.3$, and $31.7 \%$, respectively. Streptomyces djakartensis 4AS_MO2 gave the best decrease $(63.1 \%)$ in common scab disease followed by Streptomyces rochei 5AS_MO3 (53.8\%), Streptomyces geysiriensis 7AS_GP8 (42.9 $\%$ ), and Streptomyces tunisiensis 8AS_BNM2 (30.4\%), respectively (Table 6).

Table (6): Influence of different isolates of non-pathogenic species of Streptomyces on common scab severity

\begin{tabular}{|l|c|c|}
\hline \multicolumn{1}{|c|}{ isolate } & scab index $\%$ & $\begin{array}{c}\text { Disease decrease } \\
\%\end{array}$ \\
\hline Streptomyces geysiriensis 7AS_GP8 & 39.1 & 42.9 \\
\hline Streptomyces tunisiensis 8AS_BNM2 & 47.7 & 30.4 \\
\hline Streptomyces djakartensis 4AS_MO2 & 25.3 & 63.1 \\
\hline Streptomyces rochei 5AS_MO3 & 31.7 & 53.8 \\
\hline Control (+) & 68.6 & 00.0 \\
\hline Control (-) & 00.0 & - \\
\hline L.S.D. 0.05 & 3.4 & 2.9 \\
\hline
\end{tabular}

\section{D is c us sion}

The common scab of potatoes was placed among the most five serious diseases of potatoes (Sagova-Mareckova et al., 2015), and became a marketing problem for potato growers in Egypt (El-Sheikh et al., 2012 and Abd El-Rahman et al. 2018). It has been described that some nonpathogenic Streptomyces spp. are used to control pathogenic Streptomyces strains that cause potato common scab (Hiltunen et al., 2009 and Wanner et al., 2014).

In the present study, eight out of twenty-five isolates of Streptomyces, recovered from four different locations and three different crops in Egypt, showed the potential to inhibit the growth of Streptomyces scabies. The partial 16S rRNA gene sequences of five of these eight isolates showed 99.13 to $99.67 \%$ similarity with Streptomyces rochei strain NRRL B-1559. Streptomyces rochei produces antimicrobial compounds such as streptothricin and there are experiments to use it for biological control of soil-borne fungal plant pathogens (Anukool et al., 2004 and Kanini et al., 2013). The other three isolates of Streptomyces showed 99.73, 99.60, and $100 \%$ similarity with Streptomyces geysiriensis strain NRRL_B-12102, Streptomyces

Egypt. J. Phytopathol., Vol. 47, No. 1 (2019) 
tunisiensis strain CN-207, and Streptomyces djakartensis strain NBRC 15409, respectively. Streptomyces geysiriensis has been isolated from the soil and produces antibacterial antibiotic, moenomycin (Komatsu et al., 1980). Streptomyces tunisiensis has been isolated from forest soil in Tunisia and has antibacterial activity against Staphylococcus species and several other Gram-positive and Gram-negative bacteria (Slama et al., 2014). Streptomyces djakartensis has been isolated from soil and produces $\mathrm{N}$-acetyltryptamine (Zhang et al., 2013). The maximum inhibition zone diameter $(66.7 \mathrm{~mm})$ against Streptomyces scabies was recorded by the Streptomyces djakartensis 4AS_MO2. Two compounds were isolated from Streptomyces djakartensis ( $N$-acetyltryptamine and $(E)-2-$ methoxy-1, 4 naphthoquinone-1-oxime) and showed significant antibacterial activities against Bacillus cereus, Bacillus subtilis, Staphylococcus aureus, Escherichia coli, Pseudomonas aeruginosa, Pseuomonas syringaepv. Actinidiae and Erwinia carotovora (Zhang et al., 2013). Streptomyces djakartensis 4AS_MO2 gave the best decrease $(63.1 \%)$ in common scab disease, followed by Streptomyces rochei 5AS_MO3 (53.8\%), Streptomyces geysiriensis 7AS_GP8 (42.9\%) and Streptomyces tunisiensis 8AS_BNM2 (30.4\%) in pots experiment, respectively. Application of Streptomyces rochei as a biocontrol agent against Fusarium oxysporum protect tomato seeds infection in vivo (Kanini et al., 2013). Therefore, this experiment showed that Streptomyces djakartensis 4AS_MO2 and Streptomyces rochei 5AS_MO3 provided promising results as potential biocontrol agents against Streptomyces scabies. Less promising results were obtained by Streptomyces geysiriensis 7AS_GP8 and Streptomyces tunisiensis 8AS_BNM2. More experiments should be conducted in this regard. Further detailed field studies may be advised.

\section{References}

Abd El-Rahman, A.F.; El-kafrawy, A.A.; Abd El-hafez, O.A. and Abd El-Ghany, R.E.A. 2018. Evaluation of some fungicides effectiveness in control of blackleg and common scab of potato. Egyptian Journal of Agricultural Research, 96(4): 1307-1324.

Abd El-Rahman, A.F. and Shaheen, H.A. 2016. Biological control of the brown rot of potato, Ralstonia solanacearum and effect of bacterization with antagonists on promotion of potato growth. Egyptian J. Biol. Pest Control, 26(4): 733-739

Anukool, U.; Gaze, W.H. and Wellington, E.M.H. 2004. In situ monitoring of Streptothricin production by Streptomyces rochei F20 in soil and rhizosphere. Appl. Environ. Microbiol., 70: 5222-5228.

Arifuzzaman, M.; Khatun, M.R. and Rahman, H. 2010. Isolation and screening of actinomycetes from Sundarbans soil for antibacterial activity. Afr. J. Biotechnol., 9: 4615-4619. 
Arora, R.K. and Khurama, S.M. P. 2004. Major fungal and bacterial diseases of potato and their management. In: Mukerji KG (ed) Fruit and Vegetable Diseases. Kluwer Academic Publishers, New York, pp 189-231.

Cook, A.E. and Meyers, P.R. 2003. Rapid identification of filamentous actinomycetes to the genus level using genus-specific 16S rRNA gene restriction fragment patterns. International Journal of Systematic and Evolutionary Microbiology, 53: 1907-1915.

El-Sheikh, M.A. 2010. Common scab of potato as affected by soil mineral elements and tuber chemical constituents. J. Agric. and Env. Sci. Alex. Univ. Egypt, 9(2): $1-26$.

El-Sheikh, M.A.; El-Kazzaz, S.A.; El-Argawy, E. and Ghozlan, M.H. 2012. Factors affecting thaxtomin A production by Streptomyces scabies in Egypt. Egypt. J. Phytopathol., 40(2): 131-147.

FAOSTAT, 2018. Food and Agriculture Data. Crops. http://www.fao.org

Guindon, S.; Dufayard, J.F.; Lefort, V.; Anisimova, M.; Hordijk, W. and Gascuel, O. 2010. New algorithms and methods to estimate maximum-likelihood phylogenies: assessing the performance of PhyML 3.0. Syst Biol., 59(3):307-321.

Hiltunen, L.H.; Ojanpera, T.; Kortemaa, H.; Richter, E.; Lehtonen, M.J. and Valkonen, J.P.T. 2009. Interactions and biocontrol of pathogenic Streptomyces strains co-occurring in potato scab lesions. J. Appl. Microbiol., 106: 199-212.

Huerta-Cepas, J.; Serra, F. and Bork, P. 2016. ETE 3: Reconstruction, Analysis, and Visualization of Phylogenomic Data. Mol. Biol. Evol., 33(6):1635-1638.

Janaki, T.; Nayak, B.K. and Ganesan, T. 2014. Different pre-treatment methods in selective isolation of Actinomycetes from mangrove sediments of Ariyankuppam back water estuary, Puducherry. Int. J. Adv. Res. Biol. Sci., 1(6): 154-163.

Kanini, G.S.; Katsifas, E.A.; Savvides, A.L. and Karagouni, A.D. 2013. Streptomyces rochei ACTA1551, an indigenous Greek isolate studied as a potential biocontrol agent against Fusarium oxysporum f.sp. lycopersici. Bio. Med. Res. Int., 2013: Article ID 387230, 10 pp.

Komatsu, N.; Kimura, K.; Abe, S. and Kagitani, Y. $1980 . \quad$ Streptomyces spadicogriseus, a new species producing anthramycin. J. Antibiot., 33(1): 5460.

Lee, Y.K.; Kim, H.W.; Liu, C.L. and Lee, H.K. 2003. A simple method for DNA extraction from marine bacteria that produce extracellular materials. $J$. of Microbiol. Meth., 52(2): 245-250.

Egypt. J. Phytopathol., Vol. 47, No. 1 (2019) 
Lin, C.; Tsai, C.H.; Chen, P.Y.; Wu, C.Y.; Chang, Y.L.; Yang, Y.L. and Chen, Y.L. 2018. Biological control of potato common scab by Bacillus amyloliquefaciens $\mathrm{Ba}$ 01. PLoS ONE, 13(4): e0196520.

Lorang, J.; Liu, D.; Anderson, N. and Schottel, J. 1995. Identification of potato scab inducing and suppressive species of Streptomyces. Phytopathology, 85(3): 261268.

Mahdy, A.M.M.; Tawfik, A.E.; Mohamed, F.G.; Fawzy, R.N. and Abd-EL Hafez, O.A. 2014. DNA-Polymorphism among some Streptomyces scabies isolates causing potato common scab disease using RAPD-PCR technique. $2^{\text {nd }}$ International Conference on Biotechnology Applications in Agriculture (ICBAA), Benha University, Moshtohor and Hurghada, 8-12, April 2014, Egypt. Plant Pathology and Bio-techniques, 15-24.

Procopio, R.E.; Silva, I.R.; Martins, M.K.; Azevedo, J.L. and Araujo, J.M. 2012. Antibiotics produced by Streptomyces. Braz. J. Infect. Dis., 16(5): 466-471.

Rahman, M.A.; Islam, M.Z. and Islam, M.A. 2011. Antibacterial activities of Actinomycete isolates collected from soils of Rajshahi, Bangladesh. Biotechnol. Res. Int., 2011: Article ID857925.

Sagova-Mareckova, M.; Daniel, O.; Omelka, M.; Kristufek, V.; Divis, J. and Kopecky, J. 2015. Determination of factors associated with natural soil suppressivity to potato common scab. PLOS ONE, 10(1): e0116291.

Sarwar, A.; Latif, Z.; Zhang, S.; Hao, J. and Bechthold, A. 2019. A potential biocontrol agent Streptomyces violaceusniger $\mathrm{AC12} \mathrm{AB}$ for managing potato common scab. Front. Microbiol., 10:202.

Slama, N.; Mankai, H.; Ayed, A.; Mezhoud, K.; Rauch, C.; Lazim, H.; Barkallah, I.; Gtari, M. and Limam, F. 2014. Streptomyces tunisiensis sp. nov., a novel Streptomyces species with antibacterial activity. Antonie van Leeuwenhoek, 105: 377-387.

Snedecor, G.W. and Cochran, W.G. 1989. Statistical Methods. $8^{\text {th }}$ Edition, Iowa State University Press, Ames.

Stamatakis, A. 2014. RAxML version 8: a tool for phylogenetic analysis and postanalysis of large phylogenies. Bioinformatics, 30(9): 1312-1313.

Wanner, L.A. 2007. A new strain of Streptomyces causing common scab in potato. Plant Disease, 91: 352-359.

Wanner, L.A.; Kirk, W.W. and Qu, X.S. 2014. Field efficacy of nonpathogenic Streptomyces species against potato common scab. J. Appl. Microbiol., 116: 123-133. 
Wright, E.S.; Yilmaz, L.S. and Noguera, D.R. 2012. DECIPHER, a search-based approach to chimera identification for 16S rRNA sequences., 78(3): 717-725.

Zhang, W.; Wei, S.; Zhang, J. and Wu, W. 2013. Antibacterial activity composition of the fermentation broth of Streptomyces djakartensis NW35. Molecules, 18(3): 2763-2768.

Zhang, Y. and Loria, R. 2017. Emergence of novel pathogenic Streptomyces species by site-specific accretion and cis-mobilization of pathogenicity islands. Mol. Plant Microbe Interact. (MPMI), 30(1): 7.

Corresponding author: Abd El-Rahman, A.F.

E-mail: aabdelrahman2012@gmail.com

(Received 09/03/2019;

in revised form 30/03/2019)

Egypt. J. Phytopathol., Vol. 47, No. 1 (2019) 


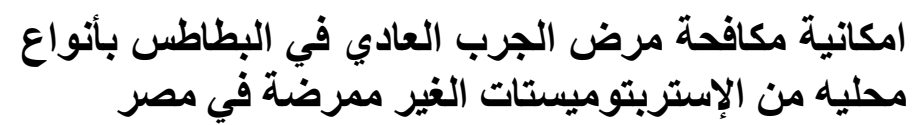

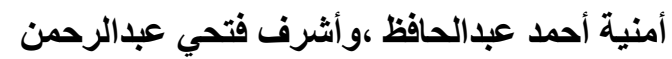

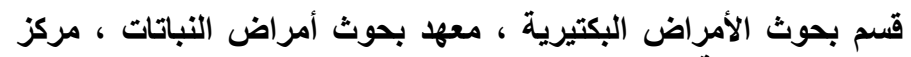

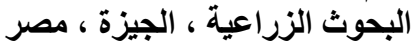

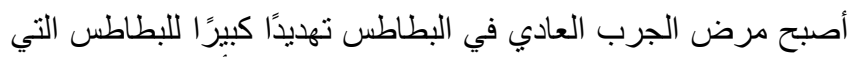

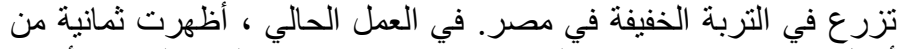

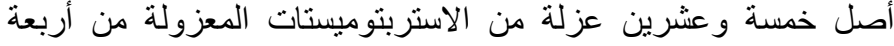

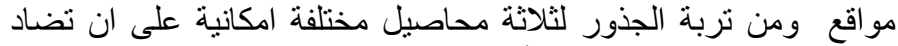

16S rRNA أظهرت تسلسيلات الجية Streptomyces scabies

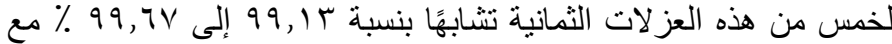

Streptomyces rochei

الثلاثة الأخرى تثابهًا بنسبة

و NRRL_B-12102 السلالة و Streptomyces geysiriensis

Streptomyces و السلالة Streptomyces tunisiensis

NBRC 15409 djakartensis

16S rRNA

تحت أرقام الانضمام MT878417 و MT878547 و MT878546 و MT87854 و

MT878478 MT878450 و MT878547 و MT8152

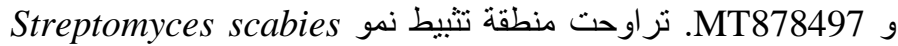
بواسطة العزلات الثمانية المضادة المختارة من الاستربتوميستات بين Streptomyces geysiriensis بون الاسترن و Streptomyces tunisiensis 8AS_BNM2 , 7AS_GB8 Streptomyces g Streptomyces djakartensis 4AS_MO2 rochei 5AS_MO3

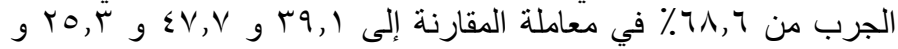

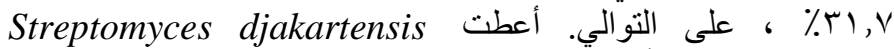
4AS_MO2

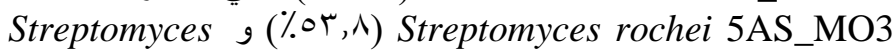
Streptomyces g (\% $\%$ r, 9$)$ geysiriensis 7AS_GB8 Streptomyces tunisiensis 8AS_BNM2 Streptomyces rochei 5AS_MO3 g djakartensis 4AS_MO2

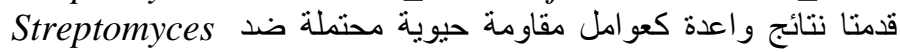
scabies 